\title{
TECNOLOGIAS DE INFORMAÇÃO E COMUNICAÇÃO NO COMPARTILHAMENTO DE APRENDIZAGENS NA EDUCAÇÃO BÁSICA
}

\author{
TECNOLOGÍAS DE INFORMACIÓN Y COMUNICACIÓN EN EL \\ INTERCAMBIO DE APRENDIZAJES EN LA EDUCACIÓN PRIMARIA
}

\section{INFORMATION AND COMMUNICATION TECHNOLOGIES IN SHARING LEARNING EXPERIENCES IN BASIC EDUCATION}

\author{
Aline DIESEL ${ }^{1}$ \\ Rogério José SCHUCK ${ }^{2}$ \\ Lara Kalkmann GOULART ${ }^{3}$ \\ Silvana Neumann MARTINS ${ }^{4}$
}

\begin{abstract}
RESUMO: O presente artigo objetiva investigar as tecnologias, digitais ou não digitais, utilizadas para promover o compartilhamento de aprendizagens decorrentes do ensino pela pesquisa na Educação Básica. Para tanto, seguiu-se com a abordagem qualitativa, sendo os dados coletados mediante a realização de entrevista semiestruturada com sete professores da Educação Básica, que trabalham com diferentes áreas (História, Pedagogia, Informática e Geografia) na rede pública e privada da região do Vale do Taquari/RS/BRA. Além disso, os sujeitos envolvidos são mestrandos do Programa de Pós-Graduação em Ensino de uma Instituição de Ensino Superior. Para a análise dos dados coletados utilizou-se a análise de conteúdo. O aporte teórico utilizado para fundamentar este estudo baseia-se nos pressupostos do ensino pela pesquisa e na relação entre tecnologia e práticas pedagógicas. Os dados coletados permitiram construir duas categorias de análise: a) aprendizagens compartilhadas em recursos tecnológicos imateriais; b) aprendizagens compartilhadas em recursos tecnológicos materiais. Os resultados apontam para a importância da produção de cartazes e painéis, assim como o uso da lousa digital, da internet, de programas para montagem de jogos e animações junto aos processos de ensino e de aprendizagem na Educação Básica.
\end{abstract}

PALAVRAS-CHAVES: Tecnologias de informação e comunicação. Educar pela Pesquisa. Compartilhamento de aprendizagens. Educação Básica.

\footnotetext{
${ }^{1}$ Universidade do Vale do Taquari (Univates), Lajeado - RS - Brasil. Mestranda do Programa de PósGraduação em Ensino pela Univates. Bolsista do Prosup/Capes. E-mail: aline.diesel@ hotmail.com.

${ }^{2}$ Universidade do Vale do Taquari (Univates), Lajeado - RS - Brasil. Mestrado e Doutorado em Filosofia pela PUCRS. Docente permanente do Mestrado Profissional em Ensino de Ciências Exatas e do Mestrado Acadêmico em Ensino da Univates. E-mail: rogerios@univates.br.

${ }^{3}$ Universidade do Vale do Taquari (Univates), Lajeado - RS - Brasil. Graduanda em Psicologia pela Univates. Bolsista de Iniciação Científica. E-mail: lara.goulart@univates.br

${ }^{4}$ Universidade do Vale do Taquari (Univates), Lajeado - RS - Brasil. Mestrado e Doutorado em Educação pela PUCRS. Docente permanente do Mestrado Profissional em Ensino de Ciências Exatas e do Mestrado Acadêmico em Ensino da Univates. E-mail: smartins@ univates.br.
} 
RESUMEN: Este trabajo tiene por objetivo investigar las tecnologías, digitales o no digitales, usadas para promover el intercambio de aprendizajes provenientes de la enseñanza por investigación en la educación primaria. Para éste fin se siguió un enfoque cualitativo, el instrumento usado para la recolección de datos fue la entrevista semi estructurada, aplicada a un grupo de siete profesores de educación primaria de diferentes áreas (Historia, Pedagogía, Informática y Geografía), estos profesores pertenecen a escuelas públicas y privadas, que están ubicadas en el Vale do Taquari en el estado de Rio Grande do Sul, Brasil. Adicionalmente, los integrantes del grupo de professores, también son estudiantes de maestría en Enseñanza (Ensino) en una institución de ensino superior situada en el mismo lugar. Para el análisis de los datos recolectados se utilizó la metodología de análisis de contenido. El aporte teórico en el que se basa está pesquisa es tomado de la enseñanza por investigación y en la relación entre tecnología y procedimientos pedagógicos. Los datos recolectados permitirán construir dos categorías de análisis: a) aprendizajes intercambiados con recursos tecnológicos inmateriales; b) aprendizajes intercambiados con recursos tecnológicos materiales. Los resultados indican la importancia de la producción de carteleras y paneles, así como el uso de tableros digitales, de internet, de programas de programación de juegos y animaciones; todos estes concomitantes con los procesos de enseñanza y aprendizaje en la educación primaria.

PALABRAS CLAVES: Tecnologías de Información y Comunicación. Educar por la Investigación. Intercambio de aprendizajes. Educación primaria.

ABSTRACT: The purpose of this article is to investigate both digital and non-digital technologies used to promote the sharing of learning experiences in learning through research in Basic Education. For such, a qualitative approach was followed, with data being gathered through a semistructured interview with seven Basic Education teachers working in different areas (History, Pedagogy, Computing and Geography) in both public and private schools in the Vale do Taquari/RS/BRA region. Moreover, the individuals involved are undergraduate Master Degree at the Post-Graduation Teaching Program at a Higher Education Institution. Content analysis was used to analyze the gathered data. The theoretical foundation used for this study is based on the teaching through research presumptions and in the relation between technology and pedagogical practices. The collected data allowed for the construction of two analysis categories: a) learning experiences shared through immaterial technological resources; b) learning experiences shared through material technological resources. The results point towards the importance of producing posters and panels, as well as using the digital board, the Internet, game assembly programs and animations together with the teaching and learning processes in Basic Education.

KEYWORDS: Information and communication technologies. Educating through research. Sharing learning experiences. Basic Education.

\section{Introdução}

Os avanços tecnológicos trazem novas possibilidades para que professores, alunos e demais indivíduos possam se relacionar e aprender. As tecnologias de 
informação e comunicação, sendo digitais ou não, possibilitam uma verdadeira transformação no campo educacional, permitindo conexão entre os envolvidos, para que possam discutir elementos educacionais com igualdade de condições.

Essa interatividade também aproxima da sala de aula outro recurso valioso para a construção do conhecimento: a pesquisa. A grande vantagem dessa abordagem parece estar no envolvimento ativo e reflexivo permanente tanto dos alunos quanto dos professores, contribuindo para a formação de sujeitos comprometidos com seu papel de cidadãos na sociedade.

O presente estudo propõe-se a investigar as tecnologias digitais ou não digitais, utilizadas para promover o compartilhamento de aprendizagens decorrentes do ensino pela pesquisa na Educação Básica. A motivação por essa temática surgiu a partir de investigações que integram o projeto de pesquisa "Iniciação à Pesquisa, TICs e Ensino: do Sul ao Norte e Nordeste do Brasil", o qual está vinculado ao Programa de PósGraduação em Ensino e ao Programa de Pós-Graduação em Ensino de Ciências Exatas, do Centro Universitário UNIVATES, situado em Lajeado/RS/BRA.

A fim de alcançar o objetivo proposto, desenvolveu-se uma pesquisa com abordagem qualitativa, a qual busca elementos relevantes nos depoimentos dos sujeitos envolvidos no estudo. Para o tratamento dos dados utilizou-se a técnica da análise de conteúdo (BARDIN, 2012). Esse método compreende a escolha do material a ser submetido à análise, a formulação do objetivo do estudo e a elaboração de indicadores que fundamentam a interpretação final. A coleta de dados se deu mediante a realização de entrevista semiestruturada com sete professores da Educação Básica, que trabalham com diferentes áreas (História, Pedagogia, Informática e Geografia) na rede pública e privada. Além disso, os sujeitos envolvidos são mestrandos do Programa de PósGraduação em Ensino da UNIVATES.

O aporte teórico utilizado para fundamentar este estudo baseia-se nos pressupostos do ensino pela pesquisa, pautadas por Demo (2011) Moraes, Galiazzi e Ramos (2002) e Moraes (2002). Já a relação entre tecnologia e práticas pedagógicas é sugeridas por Levy (1999) e Kenski (2015), entre outros autores.

Antes de mais nada, é preciso deixar claro que, neste estudo, os termos tecnologias de informação e comunicação (TICs) e tecnologias digitais de informação e comunicação (TDICs) são diferenciados. Enquanto que o primeiro é abrangente, abarcando as tecnologias educacionais de uma forma ampla, inclusive lápis e caderno, o 
segundo refere-se unicamente às tecnologias digitais, que são as possibilitadas pela conexão à internet.

Tendo sido contextualizado este estudo, apresenta-se a sua estrutura, que está dividida em mais quatro etapas. Inicialmente, são apresentados os pressupostos teóricos que fundamentam este estudo, alicerçados nos pressupostos da pesquisa no ensino e das tecnologias digitais de informação e comunicação (TDICs) e suas interfaces com o compartilhamento de aprendizagens em sala de aula. A seguir, são traçados os procedimentos metodológicos adotados no desenvolvimento do estudo, que é seguido pela análise e discussão dos dados coletados. Por fim, são traçadas as ponderações finais possibilitadas pelos resultados da investigação.

\section{Pressupostos teóricos}

\section{A necessidade da pesquisa na Educação Básica}

As mudanças pelas quais a sociedade do século XXI vem passando envolvem o campo da cultura, da religião, da ética e do conhecimento, e decorrem de um processo de globalização. Assim, na concepção de Behrens (2013), a educação é tida como o alicerce para os ideais de justiça, de paz, de solidariedade e de liberdade.

Diante disso, a autora é categórica ao considerar que

[...] o aluno precisa ultrapassar o papel de passivo, de escutar, ler, decorar e de repetidor fiel dos ensinamentos do professor e tornar-se criativo, crítico, pesquisador e atuante, pra produzir conhecimento. Em parceria, professores e alunos precisam buscar um processo de auto-organização para acessar a informação, analisar, refletir e elaborar com autonomia o conhecimento. O volume de informações não permite abranger todos os conteúdos que caracterizam uma área do conhecimento. Portanto, professores e alunos precisam aprender a aprender como acessar a informação, onde buscá-la e o que fazer com ela (BEHRENS, 2013, p. 77).

Nesse viés é que se insere a pesquisa na escola. De acordo com Demo (2011, p. 7), a abordagem do educar pela pesquisa tem quatro pressupostos fundamentais:

- a convicção de que a educação pela pesquisa é a especificidade mais própria da educação escolar e acadêmica,

- o reconhecimento de que o questionamento reconstrutivo com qualidade formal e política é o cerne do processo de pesquisa, 
- a necessidade de fazer da pesquisa atitude cotidiana no professor e no aluno,

- e a definição de educação como processo de formação da competência histórica humana.

É por isso que utilizar-se da pesquisa em sala de aula, ou seja, da investigação, significa criar um novo caminho para a aprendizagem, em que os alunos deixam de ser passivos na aprendizagem, aprendendo a lidar de forma autônoma com alguns princípios da pesquisa, a citar: “[...] o questionamento, a construção de argumentos, a construção escrita e o permanente diálogo entre situações do cotidiano e conteúdos escolares" (SILVA, 2012, p. 22).

A fim de justificar a necessidade da postura ativa dos estudantes, reportamo-nos a Moraes, Galiazzi e Ramos (2002). Esses autores justificam a necessidade da pesquisa em sala de aula, comparando metaforicamente a vida do indivíduo ao movimento de um rio que corre em direção ao mar. O rio arrasta tudo o que está em seu leito, possibilitando pouca reação aos que se deixam levar. "Apenas alguns navegam o rio de modo consciente e são estes que têm condições de influir no fluxo das águas, redirecionar o rumo do movimento, transformar o rio" (MORAES; GALIAZZI; RAMOS, 2002, p. 10).

Com essa analogia, os autores mencionam que adotar uma prática pedagógica centrada na pesquisa pode ser uma das maneiras de influir no fluxo do rio. Ou seja, de envolver tanto alunos e professor num processo ativo de questionar constantemente as verdades implícitas e explícitas, propiciando a construção de argumentos que levem a novas verdades.

Nesta mesma linha de pensamento, Demo (2011) apresenta o conceito de questionamento reconstrutivo como sendo um dos alicerces da Educação Pela Pesquisa, pois desafia o aluno a aprender a aprender, e não a copiar e a reproduzir. Moraes (2002) detalha melhor essa abordagem mencionando que a busca por conhecimentos disponíveis em livros, internet, etc., no intuito de obter informações para um questionamento, não deve ser o objetivo final do trabalho e sim o processo. "Os alunos devem, além de procurar material, interpretar o que foi encontrado, criticar e formular novas interpretações, realizando, assim, o questionamento reconstrutivo" (MORAES, 2002, p. 94).

Voltando a Moraes, Galiazzi e Ramos (2002), só o questionamento não é suficiente para a efetivação da aprendizagem, sendo necessário construir uma nova 
hipótese acerca da temática investigada e reunir argumentos para fundamentá-la. Isso implica, na visão dos autores, um processo de leitura, discussão e reflexão constante, que pode ser tanto em nível individual como em grupo.

Atrelado ao questionamento e à argumentação, os autores ainda mencionam a importância da comunicação, que pressupõe o compartilhamento das novas descobertas pela pesquisa, mesmo que provisórias, entre os sujeitos, para que estes também as analisem e critiquem, de modo a validá-las:

É importante que a pesquisa em sala de aula atinja um estágio de comunicar resultados, de compartilhar novas compreensões, de manifestar novo estado de ser, do fazer e do conhecer, o que contribui para a sua validação na comunidade em que esse processo está se dando (MORAES; GALIAZZI; RAMOS, 2002, p. 19).

Sugerem que esse compartilhamento se dá em dois momentos. O primeiro acontece dentro do próprio grupo que desenvolve a pesquisa. Trata-se de falar e escrever a descoberta, preocupando-se em torná-la compreensível para os outros. Já o segundo momento propõe a divulgação propriamente dista dos resultados alcançados para uma comunidade mais ampla.

Por fim, os autores salientam ainda que, ao proporcionar a pesquisa na sala de aula, mais importante do que o compartilhamento dos saberes, está o exercício das habilidades de questionar, de construir argumentos com qualidade e saber socializar os resultados à medida que são produzidos (MORAES; GALIAZZI; RAMOS, 2002).

Demo (2002, p. 21) valoriza o papel do professor nesse processo: “Quando nada existe, deve entrar o professor como motivação ininterrupta da pesquisa, multiplicando para o aluno oportunidades de praticar a busca de materiais, que ele mesmo procura e traz".

Diante dos aspectos levantados, em coerência com o pensamento de Demo (2011, p. 7-8), podemos afirmar que “[...] a base da educação escolar é a pesquisa, não a aula, ou o ambiente de socialização, ou a ambiência física, ou o mero contato entre professor e aluno". Segundo o autor, é daí que forma-se um sujeito que reconstrói-se permanentemente pelo questionamento, sendo que a "[...] pesquisa precisa ser internalizada como atitude cotidiana, não apenas como atividade especial, de agente especial, para momentos e salários especiais. Ao contrário, representa sobretudo a maneira consciente e contribuitiva de andar na vida, todo dia, toda hora (DEMO, 2011, p. 12-13). 
Na próxima etapa, apresentam-se algumas considerações especificamente acerca do ponto central dessa pesquisa, qual seja, o compartilhamento de aprendizagens. Conforme mencionado, esta se constitui a última fase do processo de educar pela pesquisa, contudo, não a mais importante.

\section{A pesquisa e o compartilhamento de aprendizagens}

O dicionário traz o conceito de compartilhar como sendo "1. Ter parte em, participar de. 2. Partilhar com alguém.” (FERREIRA, 2010). Vale também referir sinônimos do termo "compartilhar", segundo o dicionário online de sinônimos: associar, distribuir, partilhar, compartir, repartir, dividir.

A partir disso, percebe-se que o termo compartilhamento de aprendizagem na sala de aula está relacionado com partilhar com outra pessoa os saberes adquiridos durante determinado estudo. Compartilhar aprendizagens pressupõe distribuir, partilhar, repartir ou dividir o aprendizado com outros sujeitos.

Embora haja pouca referência acerca dessa estratégia em sala de aula, trata-se de um valioso recurso para estimular a interação entre os sujeitos, na perspectiva do que ensina Vygotsky. Para o estudioso, a intervenção de outras pessoas no desenvolvimento individual é evidente num processo de aprendizagem, sobretudo na escola, onde o aprendizado é o objetivo (OLIVEIRA, 1995). Em razão disso, os processos pedagógicos devem ser interacionais.

O compartilhamento de aprendizagens também pode ser alinhavado a partir da ideia de aprendizagem colaborativa, alicerçada na ideia de aprender e trabalhar em grupo. Embora este seja um termo voltado para a aprendizagem online, alguns pressupostos aproximam-se do compartilhamento de aprendizagens. Há uma parceria de auxílio mútuo entre os estudantes no processo de aprendizagem, o que torna a interação a base da aprendizagem. Além disso, há de se considerar também que as "[...] práticas colaborativas proporcionam aprendizagens diversas, fazendo circular muito mais informações. A troca e a partilha de experiências aumenta de forma significativa a quantidade de soluções e ideias e a qualidade das opções realizadas" (SERAFIM; PIMENTEL; SOUZA DO Ó, 2008, p. 8)

Numa atividade de aprendizagem compartilhada, é imprescindível ao educador intervir, provocando avanços que não ocorreriam de forma espontânea. Assim, fica evidente que a escola tem de conduzir o trabalho educativo para estágios de 
desenvolvimento ainda não alcançados pelos estudantes, impulsionando para novos patamares de conhecimento e novas conquistas, a partir daquilo que o educando já sabe.

\section{TDICs no compartilhamento das aprendizagens}

Como bem sabemos, em sentido amplo, as tecnologias estão tão próximas e introduzidas nas rotinas diárias que nem se percebe mais que não são coisas naturais, a exemplo do lápis, dos cadernos, das canetas, entre tantos outros equipamentos que foram planejados e construídos para que se possa ler, escrever, ensinar e aprender. Contudo, de acordo com Kenski (2015), quando nos referimos às tecnologias hoje, reportamo-nos muito mais a processos e produtos do espaço virtual, que têm como matéria-prima a informação. Os avanços tecnológicos constantes levaram à criação de redes internacionais de computador (Internet) e tornaram-no um equipamento pessoal. Com isso, a comunicação instantânea tornou-se global, facilitando o acesso à informação. Nessa perspectiva, vivenciamos um período no qual emergem novas formas de relacionar-se com o mundo e com o conhecimento, e que passam a exigir novas habilidades cognitivas.

Constitui-se, assim, o ciberespaço, definido por Lévy (1999, p. 92) como “[...] espaço de comunicação aberto pela interconexão mundial dos computadores e das memórias dos computadores". Ainda de acordo com o autor, o ciberespaço é alimentado por informações, o que o tornará o principal canal de comunicação e suporte de memória da humanidade.

Reportando-nos para o campo educacional, diante do conhecimento, a aproximação das TDICs deve “[...] possibilitar a inserção do aluno no mundo, não para repeti-lo passivamente, mas para que possa intervir de forma crítica, orientando-se por princípios éticos e de cidadania" (KUENZER, 2003, p. 426). Para tanto, de acordo com Moraes (2002), é imprescindível oferecer situações de aprendizagem em que os estudantes estejam verdadeiramente envolvidos no processo, podendo manipular, explorar, observar e discutir o objeto de estudo. Nessa perspectiva é que se constrói a interface entre a pesquisa na sala de aula e as TDICs.

Considerando que o ensinar pela pesquisa constitui-se por questionamento, construção de argumentos e compartilhamento das novas descobertas, Moraes (2002) considera que as TDICs podem integrar cada uma dessas etapas: 
[...] através da busca e recuperação de informações, o estudante terá em suas mãos um referencial teórico bastante forte para $o$ questionamento e construção de seus argumentos. Já os serviços para a troca de ideias e informações num grupo de pessoas e entre grupos é bastante útil para a comunicação e crítica dos argumentos construídos (MORAES, 2002, p. 89).

Nesse sentido, as tecnologias podem fomentar a busca por informações teóricas acerca da temática do questionamento levantado. Essas informações pesquisadas podem servir de base para a troca de ideias entre o grupo de alunos, que, de acordo com a pesquisadora, é fundamental para a constituição dos argumentos.

Sancho (2002, p. 17) corrobora com esse entendimento: “[...] o computador e suas tecnologias associadas, sobretudo a internet, tornam-se mecanismos prodigiosos que transformam o que tocam, ou quem tocam, e são capazes, inclusive, de fazer o que é impossível para seus criadores.” Exemplificando possibilidades do uso desses recursos no campo educacional, o autor menciona a motivação dos alunos e a criação de redes de colaboração.

É ainda relevante, para os propósitos desta pesquisa, mencionar que, embora venha se falando há anos das vantagens do uso das TDICs na sala de aula, poucos ainda são os professores que realmente utilizam-nas em suas práticas pedagógicas. De acordo Sancho (2002, p. 19), “A principal dificuldade para transformar os contextos de ensino com a incorporação de tecnologias diversificadas [...] parece se encontrar no fato de que a tipologia de ensino dominante na escola é a centrada no professor", em que a escola mantém uma organização e cultura tradicionais, segundo a qual ensinar é explicar, aprender é escutar e o conhecimento é o que contêm os livros didáticos.

Com base nesses aportes teóricos apresentados, busca-se investigar as tecnologias, sejam elas digitais ou não, utilizadas para promover o compartilhamento de aprendizagens decorrentes de um ensino pautado na pesquisa, em diferentes níveis de ensino da Educação Básica. Antes de apresentar os dados aos quais se chegou, descreveremos os caminhos metodológicos seguidos.

\section{Procedimentos metodológicos}

Para elucidar o objetivo proposto, qual seja, investigar as tecnologias (digitais ou não) utilizadas para promover o compartilhamento de aprendizagens decorrentes do ensino pela pesquisa na Educação Básica, desenvolveu-se uma pesquisa com abordagem qualitativa, em que há o “[...] interesse em apanhar também o lado subjetivo 
dos fenômenos, buscando depoimentos que se transformem dados relevantes" (DEMO, 2013, 118).

A coleta de dados se deu mediante a realização de entrevista semiestruturada com sete professores da Educação Básica, atuantes na rede pública e privada, e que trabalham com diferentes áreas (História, Pedagogia, Informática, entre outras). Além disso, os sujeitos envolvidos são mestrandos do Programa de Pós-Graduação em Ensino de um Centro Universitário localizado no interior do Rio Grande do Sul - BRA.

As entrevistas constituem em um valioso instrumento de recolha de dados numa abordagem qualitativa da pesquisa. De acordo com Richardson (1999, p. 207), “A melhor situação para participar na mente de outro ser humano é a interação face a face, pois tem o caráter, inquestionável, de proximidade entre as pessoas, que proporciona as melhores possibilidades de penetrar na mente, vida e definição dos indivíduos". Nessa investigação, as entrevistas foram semiestruturadas, nas quais o pesquisador elabora perguntas previamente, mas o entrevistado tem a liberdade de se expressar (RICHARDSON, 1999).

Para a análise dos dados coletados utilizou-se a análise de conteúdo. Segundo Bardin, (2012) esse método compreende a escolha do material a ser submetido à análise, a formulação do objetivo do estudo e a elaboração de indicadores que fundamentam a interpretação final. Neste estudo, foram definidas as seguintes categorias de análise: a) aprendizagens compartilhadas em recursos tecnológicos materiais; b) aprendizagens compartilhadas em recursos tecnológicos imateriais.

Destaca-se, ainda, que os sujeitos envolvidos neste estudo preencheram o Termo de Consentimento Livre e Esclarecido (TCLE), no qual autorizam a publicação das informações para fins educacionais, estando garantido o sigilo à identidade. Assim, os professores participantes deste estudo serão aqui referidos por A1, A2, e assim sucessivamente, até A7.

\section{Análise e discussão dos resultados}

A partir da análise das informações coletados com as entrevistas, realizou-se um recorte das falas, levando em conta os apontamentos que tiveram maior relevância para o objetivo deste estudo. Nesta seção, cada uma das categorias é apresentada, possibilitando a triangulação entre o propósito deste estudo, os aspectos teóricos levantados, e os dados coletados. 


\section{a) Aprendizagens compartilhadas em recursos tecnológicos imateriais}

Nesta categoria, são apresentados os dados que emergiram acerca das situações de aprendizagens compartilhadas em recursos tecnológicos imateriais. Entre esses recursos imateriais, configura-se, basicamente, a oralidade.

No início da civilização, a comunicação era primária, limitada à oralidade. A perpetuação da memória do grupo, sua cultura e identidade se restringia a gêneros orais, como cantos, poesias, narrativas de lendas e histórias da tribo (KENSKI, 2015). Atualmente, “[...] ainda é a linguagem oral a nossa principal forma de comunicação e troca de informações" (KENSKI, 2015, p. 28-29).

Assim é também na escola, onde alunos e professores usam, preferencialmente, a comunicação oral para interagir e também para compartilhar aprendizagens. Essa dinâmica foi observada nas falas de A1 e A2, que mencionaram compartilhar aprendizagens em mostras de trabalhos e apresentações em sala de aula:

Tem mostra de trabalhos que a gente apresenta uma vez por ano. Ou dependendo do tipo de trabalho a gente chama os pais na sala de aula. (Al)

Eu compartilho a aprendizagem deles fazendo mostra de trabalhos, eu utilizo muitas apresentações, algumas vezes um aluno apresenta algo que ele pesquisou e o outro não, porque às vezes é o desejo de um e do outro não. Então, assim, eu consigo dar muita voz pra essa aprendizagem que eles têm, dando espaço na sala pra que eles oralizem o que eles aprenderam, pra que eles exponham os desenhos deles, pra que eles exponham o que eles estão aprendendo, que eles tão pesquisando, tanto na escola quanto em casa também. (A2)

Percebe-se que a professora A2, que trabalha com classes de Ensino Médio, utiliza a abordagem do educar pela pesquisa em sua prática pedagógica. Em seu discurso, evidencia-se que valoriza o processo como um todo, não dando ênfase apenas para o pesquisar, ou para o compartilhar, conforme mencionado por Moraes, Galiazzi e Ramos (2002).

Essa mesma perspectiva está nas falas de A4, professor de Ciências do Ensino Fundamental, A5, professora de História e Geografia do Ensino Fundamental e Médio, e A6, professor de Filosofia do Ensino Médio:

Procuro observar bem o que eles trazem, as vivências que eles têm, socializar com os demais. E a medida do possível fazer links com os 
conteúdos, para que todos possam estar trocando informação $e$ enriquecendo mais a aprendizagem. (A4)

Sozinha já não consigo mais dar conta de tudo. Estou sempre tentando trazer e partilhar o meu saber com o deles. Porque eles trazem muita informação também. E acho que isso é uma coisa que os professores têm que ter consciência, que ele tem que estar aberto a essa troca. (A5)

Muito do que eu leio, eu trabalho com eles também. Assim, a questão de leitura de revistas, de jornais, referencial teórico. A questão deles lerem em voz alta a produção deles, os textos, as poesias, a questão da simples resposta, uma resposta que é mais pessoal. Então essa é uma forma de compartilhar também. De tu trocar conhecimento [...]. (A6)

Destaca-se ainda outro aspecto relevante, apontado por A2 ao mencionar que, quando promoveu momentos de compartilhar as aprendizagens dos seus estudantes, os saberes conectaram-se a outros saberes. Se não bastasse isso, novos pontos foram sucitando a curiosidade dos estudantes, formando um ciclo:

Então é como se fosse uma corrente assim que vai, que as aprendizagens vão se conectando, vão se encaixando assim. Mas ao mesmo tempo que pode surtir, é, curiosidade em um, em outros pode não surtir. (A2)

Essa linha de pensamento corrobora com Demo (2002), que considera a curiosidade o grande propulsor do questionamento e, consequentemente, da pesquisa na educação. A rotina tradicional do ambiente escolar, baseada na transmissão de conteúdos, pode suprimir essa característica fundamental do sujeito para a sua constituição como cidadão.

De fato, a criança é, por vocação, um pesquisador pertinaz, compulsivo. A escola, muitas vezes, atrapalha esta volúpia infantil, privilegiando em excesso disciplina, ordem, atenção subserviente, imitação do comportamento adulto, como se lá estivesse para escutar e fazer o que os outros the mandam (DEMO, 2002, p. 13-14).

Ainda sobre essa questão, vale ressaltar os comentários de A1, que trabalha com classes de alfabetização ( $1^{\circ}$ ano do Ensino Fundamental):

A gente aprende junto, bastante juntos assim, muitas questão eles levantam que eu não sei, eu digo pra eles que eu vou procurar junto, a gente vai junto, a gente vai pra informática, a gente vai pra biblioteca, 
ou vou pra casa e outro dia eu trago. Então a gente vai descobrindo junto assim a ideia é essa. (A1)

Nessa fala, há indícios de características de questionamento reconstrutivo, em que, conforme mencionado anteriormente, o aluno é provocado a aprender a aprender, e não a copiar e a reproduzir. $O$ conhecimento não está unicamente nas mãos do professor; cada aluno tem seu próprio conhecimento ou, se não o tiver, tem condições de buscá-los em livros, internet, entre outros. Além disso, fica implícito na fala da professora que esse saber trazido para a classe, tanto por ela quanto pelos alunos, é alvo de discussão e interpretação e crítica. "Trata-se de transformar o aprender entendido como ser ensinado, treinado, para o aprender a aprender" (DEMO, 2011, p. 30).

Ao adentrarmos a questão da interação entre saberes adquiridos oralmente, cabe refletir sobre dois aspectos relevantes na teoria de Vigotsky. O primeiro diz respeito à interação social, que pressupõe uma ação de partilha entre os sujeitos de modo que sejam ativos do processo. "O desenvolvimento e a aprendizagem dos alunos vão sendo potencializados pelas divergências, pela comparação e defesa de hipóteses e por (des)acordos" (SARMENTO, 2008, texto digital). E complementa:

\footnotetext{
É importante retomar a ideia de que, quando se fala em interação no contexto escolar, temos presente, além da relação professor-aluno, também a que ocorre entre pares como um momento ímpar para o desenvolvimento dos sujeitos. Interação essa que compreende um processo cooperativo entre os sujeitos envoltos numa situação comum. Entretanto, é necessário romper com uma visão simplista de que todas as interações provocam ou desencadeiam processos de desenvolvimento e aprendizagem, ou até mesmo possuem um valor formativo, independentemente se essas acontecem no contexto escolar ou no contexto social mais amplo (SARMENTO, 2008, texto digital).
}

Diante do exposto, pode-se dizer que a oralidade está presente no cotidiano escolar atual, sendo uma das formas mais frequentes de compartilhar as aprendizagens adquiridas numa abordagem do educar pela pesquisa. Trata-se de tecnologias imateriais disponíveis pelo professor, que não exigem nenhum tipo de recurso prévio. Como exemplos, podemos citar a mostra de trabalhos para a comunidade escolar e pais, assim como apresentações aos próprios colegas.

$\mathrm{Na}$ escola, além da oralidade, faz-se uso da escrita. Eis um recurso tecnológico auxiliar ao pensamento, que "[...] possibilita ao homem a exposição de suas ideias, deixando-o mais livre para ampliar sua capacidade de reflexão e apreensão da 
realidade" (KENSKI, 2015, p. 31). Essa tecnologia será explorada na próxima categoria.

\section{b) Aprendizagens compartilhadas em recursos tecnológicos materiais}

Os professores envolvidos no estudo manifestaram diversas formas de compartilhar as descobertas por meio de recursos tecnológicos materiais, que vão desde a organização de jornal escolar, até a elaboração de cartazes para serem expostos na própria sala, entre outros meios:

A gente não tem tanta produção escrita, tanta produção visual que nem a gente tem nas outras modalidades de ensino. Então fazer quando eles produzam alguma coisa, alguma produção legal, fazer com que eles se visualizem essa produção. "Ah! Esse é uma produção da EJA, da escola". E eu sou muito assim de divulgar, nesse sentido assim de: "ah ficou legal, temos que fazer um cartaz, temos que fazer um painel". (A3)

Diante dessas duas falas, reportando-se a realidades diferentes - A1 volta-se para crianças em fase de alfabetização, a A3 para adultos da Educação de Jovens e Adultos -, chamamos atenção para a importância que essas docentes estão dando à construção da autonomia do aluno. Ao incentivar a divulgação de algum estudo, estão valorizando o esforço do aluno envolvido e socializando com os demais os resultados. Para além disso, esta estratégia cria visibilidade e estimula o comprometimento por parte dos autores.

O mesmo também pode ser verificado no depoimento da professora A5, de Geografia, que ilustra uma situação de compartilhamento de aprendizagens em um cartaz, a partir de uma palestra de um tema relevante para a idade dos seus alunos:

Então trabalhei um textinho chamado "Globesidade". Pequenininho. E aí eles assistiram lá e eu pensei "por que eu vou agora volta pra sala de aula e vou só trabalhar geografia e regiões brasileiras?" que era o que a gente ia começar. Ai eu disse pra eles "Pessoal, o que é que ficou de legal naquilo que a gente viu?", "Que é que vocês acham?", "Como é que a gente pode mostrar para os outros que não viram essa palestra que a gente viu?". Então eles partiram: "Não, profe, a gente poderia fazer cartazes daquilo". Então tá. Então vamos, pra alertar alguns dados. Ó! Um copinho de Coca equivale a sete saches de açúcar. Vamos representar isso. Então eu sempre procuro dar mais significado ao que eles estão aprendendo. (A5) 
Na prática pedagógica dessa professora, percebe-se a sua constante preocupação em problematizar as questões que aparecem, sem deixar de trazer a discussão para contextos a partir do horizonte de compreensão dos seus alunos. Nesse sentido, reportamo-nos à Moraes, Galiazzi e Ramos (2002), que, mencionando Freire, consideram que o conhecimento surge como resposta a uma pergunta:

O questionar é dar-nos conta no fluxo do rio de que nada é definitivo, que as verdades podem tomar diferentes formas. Que somos sujeitos e que podemos influir no movimento da água. É compreender que podemos mudar, que é possível modificar-nos num sentido desejado, possivelmente melhor. Questionar é criar as condições de avançar (MORAES; GALIAZZI; RAMOS, 2002, p. 14).

Nessa perspectiva, os autores, assim como o docente entrevistado, entendem que a mola propulsora da pesquisa em sala de aula é a problematização pelo questionamento. Entretanto, o processo de construção de conhecimento não encerra na pergunta, ou simplesmente na busca de informações para responder à pergunta. Conforme mencionado anteriormente, ele é apenas o início de um ciclo que envolve a construção de argumentos, exigindo discussão e reflexão, a comunicação, ou seja, o compartilhamento das aprendizagens.

A prática pedagógica relatada por A5 remete às considerações de Moraes, Galiazzi e Ramos (2002), já mencionadas anteriormente. Para os autores, ao proporcionar a pesquisa na sala de aula, o exercício das habilidades de questionar é mais importante do que o compartilhamento dos saberes, de construir argumentos com qualidade e saber socializar os resultados à medida que são produzidos.

O professor A6 também relatou um exemplo de situações e recursos utilizados para compartilhar os saberes dos seus alunos:

Que nem agora eu trabalhei, tinha feira do livro, então um trabalhinho que eles fizeram em cima da lenda do Boi-tá-tá. Eles construíram uma cobra gigante, cada aluno a sua maneira, claro. E vimos trabalhos bem interessantes, então foi exposto na feira. Porque uma das escritoras trabalhou essa lenda. Então se trabalhou, integrou tudo. Jornais, exposições, vamos fazer exposições também, todo ano procuro fazer uma exposição (A6).

Moraes, Galiazzi e Ramos (2002) consideram que a etapa da divulgação de descobertas pode se dar dentro do próprio grupo em que a pesquisa foi efetivada, ou então para uma comunidade mais ampla. Assim, os autores entendem que deve haver 
um esforço em expressar os resultados com clareza, tornando as descobertas compreensíveis, mesmo para aqueles que não participaram diretamente do estudo. Para tanto, o processo da escrita é fundamental e deve ser construído na classe, em etapas:

[...] nesse processo do escrever, muitas versões parciais de um texto final podem ser produzidas. Cada uma delas será submetida a diferentes grupos da sala de aula para sua validação e crítica. A comunicação final vai assim sendo refinada e aperfeiçoada, ocorrendo no mesmo movimento a sua validação por um grupo cada vez mais amplo (MORAES; GALIAZZI; RAMOS, 2002, p. 20).

Conforme já exposto anteriormente, o universo de uma educação que promove uma abordagem de pesquisa aos alunos, independentemente do nível de ensino, favorece uma postura de aprendizagem colaborativa. Percebeu-se que o uso de tecnologias digitais para divulgar esses saberes não é muito difundido entre os professores entrevistados. Dos sete professores envolvidos no estudo, dois mencionaram fazer uso das tecnologias digitais, sendo um deles da disciplina de Informática.

Eu sou muito midiática, crio um blog, nesse sentido de fazer aparecer, de querer colocar pra que os outros vejam, e fazer então com que eles também se enxerguem, como estudantes. Que eles também podem estar lá na parede da escola. Acho que nesse sentido eu tento mostrar que compartilhar, nesse sentido duplo aí da palavra, a aprendizagem dos meus alunos. (A3)

A entrevistada A3 não tinha mencionado detalhes sobre a forma como ela divulga os saberes dos alunos, mas fica subjacente que se utiliza de blogs. Assim, infere-se que deve divulgar fotografias dos trabalhos, bem como comentários dos alunos. Entretanto, mais uma vez ficou evidenciada a preocupação dessa professora em valorizar seus alunos, de modo a se sentirem motivados para prosseguir nos estudos, uma vez que são estudantes da Educação de Jovens e Adultos.

Neste estudo ficou evidenciada a importância da escrita na abordagem da educação para a pesquisa, sendo que também deve-se levar em conta que o ato de registrar conduz o sujeito à reflexão e sistematização das novas descobertas. Assim, as próprias descobertas são questionadas, favorecendo a percepção de lacunas nas conclusões. "O trabalho pode então ser retomado para aperfeiçoamento e complementação" (MORAES; GALIAZZI; RAMOS, 2002, p. 20). 
Ao final desta seção, que abarca a categoria dos recursos tecnológicos materiais utilizados para compartilhar aprendizagens, os entrevistados citaram os seguintes exemplos: cartazes, jornalzinho da escola, construções artísticas e o computador.

\section{Considerações finais}

O espírito investigativo precisa ser disseminado no cotidiano das escolas, tornando-se internalizado em cada aluno e professor. Motivar os alunos desde o início da Educação Básica a uma postura investigadora, formalizando por escrito as ideias e questionamentos, aprendendo a argumentar, a redigir e planificar suas ideias desde cedo, leva o aluno a trilhar por novos caminhos, relacionando os seus achados com novas perguntas, e assim por diante. Nesta caminhada, é imprescindível que o sujeito se perceba com autor, como sujeito de direitos e deveres, de uma consciência crítica e criativa a lhe conduzir pelos caminhos do conhecimento.

Diante da busca em saber como se dá o compartilhamento de aprendizagens decorrentes do ensino pela pesquisa em diferentes etapas da Educação Básica, constatou-se que a oralidade está presente no cotidiano escolar atual, sendo uma das formas mais frequentes de compartilhar as aprendizagens adquiridas numa abordagem do educar pela pesquisa. Como exemplos, pode-se citar a mostra de trabalhos para a comunidade escolar, assim como também as apresentações de trabalhos aos colegas.

Outra questão que ficou evidenciada é que os envolvidos nos processos de ensino e de aprendizagem também mencionaram fazer uso de recursos tecnológicos materiais, tais como cartazes, jornalzinho da escola e construções artísticas. Vale ressaltar, nessa etapa, a importância da escrita no processo de pesquisar, sobretudo porque o processo de registrar exige a sistematização dos argumentos, fazendo com que as considerações sejam constantemente problematizadas e questionadas.

Por fim, pode-se concluir, também, que recursos mediados pelo uso do computador e a Internet, tais como blogs, chats, entre outros, são pouco utilizados pelos profissionais entrevistados. Disso depreende-se a necessidade de continuar investigando a fim de promover experiências de ensino e de aprendizagem por meio do uso das tecnologias digitais.

\section{REFERÊNCIAS}


BARDIN, Laurence. Análise de conteúdo. São Paulo: Edições 70, 2012.

DEMO, Pedro. Educar pela pesquisa. 9. ed. Campinas: Autores Associados, 2011.

DEMO, Pedro. Metodologia da investigação em educação. Curitiba, InterSaberes, 2013.

FERREIRA, Aurélio Buarque de Holanda. Dicionário Aurélio da língua portuguesa. 5. Ed. Curitiba, PR: Positivo, 2010.

KENSKI, Vani Moreira. Educação e tecnologias: o novo ritmo da informação. 7. ed. Campinas: Papirus, 2015.

LÉVY, Pierre. Cibercultura. São Paulo: Editora 34, 1999.

MORAES, Roque. Do ponto de interrogação ao ponto: a utilização dos recursos da internet na educação pela pesquisa. In: MORAES, Roque; LIMA, Valderez Marina do Rosário (Orgs). Pesquisa em sala de aula: tendências para a educação em novos tempos. 2. ed. Porto Alegre: EDIPUCRS, 2002.

MORAES, Roque; GALIAZZI, Maria do Carmo; RAMOS, Maurivan G. Pesquisa em sala de aula: fundamentos e pressupostos. In: MORAES, Roque; LIMA, Valderez Marina do Rosário (Orgs). Pesquisa em sala de aula: tendências para a educação em novos tempos. 2. ed. Porto Alegre: EDIPUCRS, 2002.

OLIVEIRA, Marta Kohl. Pensar a educação: Contribuições de Vygotsky. In: CASTORINA, José Antonio; FERREIRO, Emilia; LERNER, Delia; OLIVEIRA, Marta Kohl de. Piaget - Vygostsky: Novas contribuições para o detabe. Editora Ática, 1995. p. 51-84.

RICHARDSON, Roberto Jarry. et al. Pesquisa social: métodos e técnicas. 3. ed. rev. ampl. São Paulo: Atlas, 1999.

SAMENTOS, Dirléia Fanfa. Lev Vygotsky: a interação social no processo do desenvolvimento infantil. Revista do Instituto Humanistas Unisinos, São Leopoldo, n. 281, 10 nov. 2008. Entrevista concedida a Paula Fachin.

SERAFIM, Maria Lúcia.; PIMENTEL, Fernando Sílvio Cavalcante.; SOUSA DO Ó, Ana Paula de. Aprendizagem colaborativa e interatividade na web: experiências com o Google Docs no ensino de Graduação. In: $2^{\circ}$ Simpósio Hipertexto e Tecnologias na Educação - Multimodalidade e Ensino. Anais eletrônicos. Universidade Federal de Pernambuco (UFPE), 2008.

SILVA, A. S. da. Pesquisa no ensino de ciências: Estudo de caso numa organização curricular por ciclos de formação. 2012. 101 f. Dissertação (Mestrado) - Programa de Pós-Graduação Strictu Sensu Mestrado em Ensino de Ciências Extas, Centro Universitário Univates, Lajeado, dez. 2012. 


\section{Como referenciar este artigo}

DIESEL, Aline. et al. Tecnologias de informação e comunicação no compartilhamento de aprendizagens na educação básica. Revista Ibero-Americana de Estudos em Educação, Araraquara, v. 13, n. 1, p. 59-77, jan./mar. 2018. E-ISSN: 1982-5587.

Submetido em: 29/04/2016

Revisões requeridas: 05/06/2017

Aceito em: 01/07/2017 